\title{
Experience with the first 50 ex vivo lung perfusions in clinical transplantation
}

\author{
Marcelo Cypel, MD, MSc, Jonathan C. Yeung, MD, PhD, Tiago Machuca, MD, Manyin Chen, MD, \\ Lianne G. Singer, MD, Kazuhiro Yasufuku, MD, PhD, Marc de Perrot, MD, MSc, Andrew Pierre, MD, MSc, \\ Thomas K. Waddell, MD, PhD, and Shaf Keshavjee, MD, MSc
}

Objective: Normothermic ex vivo lung perfusion is a novel method to evaluate and improve the function of injured donor lungs. We reviewed our experience with 50 consecutive transplants after ex vivo lung perfusion.

\begin{abstract}
Methods: A retrospective study using prospectively collected data was performed. High-risk brain death donor lungs (defined as $\mathrm{PaO}_{2} / \mathrm{FiO}_{2}<300 \mathrm{~mm} \mathrm{Hg}$ or lungs with radiographic or clinical findings of pulmonary edema) and lungs from cardiac death donors were subjected to 4 to 6 hours of ex vivo lung perfusion. Lungs that achieved stable airway and vascular pressures and $\mathrm{PaO}_{2} / \mathrm{FIO}_{2}$ greater than $400 \mathrm{~mm} \mathrm{Hg}$ during ex vivo lung perfusion were transplanted. The primary end point was the incidence of primary graft dysfunction grade 3 at 72 hours after transplantation. End points were compared with lung transplants not treated with ex vivo lung perfusion (controls).
\end{abstract}

Results: A total of 317 lung transplants were performed during the study period (39 months). Fifty-eight ex vivo lung perfusion procedures were performed, resulting in 50 transplants ( $86 \%$ use). Of these, 22 were from cardiac death donors and 28 were from brain death donors. The mean donor $\mathrm{PaO}_{2} / \mathrm{FIO}_{2}$ was $334 \mathrm{~mm} \mathrm{Hg}$ in the ex vivo lung perfusion group and $452 \mathrm{~mm} \mathrm{Hg}$ in the control group $(P=.0001)$. The incidence of primary graft dysfunction grade 3 at 72 hours was $2 \%$ in the ex vivo lung perfusion group and $8.5 \%$ in the control group $(P=.14)$. One patient $(2 \%)$ in the ex vivo lung perfusion group and 7 patients $(2.7 \%)$ in the control group required extracorporeal lung support for primary graft dysfunction $(P=1.00)$. The median time to extubation, intensive care unit stay, and hospital length of stay were 2,4 , and 20 days, respectively, in the ex vivo lung perfusion group and 2, 4, and 23 days, respectively, in the control group $(P>.05)$. Thirty-day mortality ( $4 \%$ in the ex vivo lung perfusion group and $3.5 \%$ in the control group, $P=1.00)$ and 1 -year survival $(87 \%$ in the ex vivo lung perfusion group and $86 \%$ in the control group, $P=1.00$ ) were similar in both groups.

Conclusions: Transplantation of high-risk donor lungs after 4 to 6 hours of ex vivo lung perfusion is safe, and outcomes are similar to those of conventional transplants. Ex vivo lung perfusion improved our center use of donor lungs, accounting for $20 \%$ of our current lung transplant activity. (J Thorac Cardiovasc Surg 2012;144:1200-7)

Lung transplantation (LTx) is often the only treatment option for patients with end-stage lung disease, who will otherwise die. Despite significant advances made since the first clinically successful LTx in 1983, LTx clinicians still face some challenges. The first major obstacle is the short supply of donor organs. As the population ages, the number of patients in need of LTx is increasing; however, the supply of

From the Toronto Lung Transplant Program, University Health Network, University of Toronto, Toronto, Ontario, Canada.

Funding: Vitrolife (Gothenburg, Sweden) sponsored the Ex vivo Lung Perfusion Clinical Trial.

Disclosures: Authors have nothing to disclose with regard to commercial support.

Read at the 92nd Annual Meeting of The American Association for Thoracic Surgery, San Francisco, California, April 28-May 2, 2012.

Received for publication April 25, 2012; revisions received July 8, 2012; accepted for publication Aug 1, 2012; available ahead of print Sept 3, 2012.

Address for reprints: Shaf Keshavjee, MD, MSc, Toronto Lung Transplant Program, Toronto General Hospital, 200 Elizabeth St, 9N946, Toronto, ON, Canada (E-mail: shaf.keshavjee@uhn.ca).

$0022-5223 / \$ 36.00$

Copyright $($ c 2012 by The American Association for Thoracic Surgery

http://dx.doi.org/10.1016/j.jtcvs.2012.08.009 donor lungs has remained essentially static. Furthermore, the situation is aggravated by a low use rate of $15 \%$ to $20 \%$ of offered donor organs. ${ }^{1}$ This conservative use stems from the vulnerability of the donor lung to injury during the brain death process or during intensive care unit (ICU) management. ${ }^{2}$ Whereas management strategies in the multiorgan donor are important in preventing lung deterioration, ${ }^{3}$ organ retrieval often has to occur before the lungs have time to recover from brain death or other related injuries. ${ }^{4}$

Although maintaining organ viability using static hypothermic preservation is the widely accepted method of preserving donor lung viability after removal, ${ }^{5,6}$ the inhibition of cellular metabolism induced by hypothermia ${ }^{7}$ hinders the process of recovery and negates the possibility of assessment (testing the organ before transplant) or repair during the organ preservation period. In 2001, Steen and colleagues ${ }^{8}$ described the first transplantation after normothermic ex vivo assessment of a donor lung from a cardiac death donor (DCD). Since 2006, our group in Toronto has made significant modifications to the ex vivo lung perfusion 

Abbreviations and Acronyms
$\mathrm{BDD}=$ brain death donor
DCD $=$ cardiac death donor
ECLS $=$ extracorporeal life support
$\mathrm{EVLP}=$ ex vivo lung perfusion
ICU $=$ intensive care unit
LTx = lung transplantation
$\mathrm{P} / \mathrm{F}=\mathrm{PaO}_{2} / \mathrm{FIO}_{2}$
PGD = primary graft dysfunction

(EVLP) strategy, system, and technique. After extensive laboratory research, we performed the first prospective clinical trial of EVLP including 20 patients, demonstrating the safety of the procedure. ${ }^{9}$ We report our experience with 50 consecutive lung transplants after 4 to 6 hours of EVLP of high-risk donor lungs.

\section{MATERIALS AND METHODS Study Design}

This is a single-institution, retrospective study using prospectively collected data. Outcomes of consecutive recipients undergoing transplantation after normothermic EVLP of high-risk donor lungs ${ }^{10}$ were studied and compared with those of contemporary conventional LTx recipients. Donor lungs that met study entry criteria were retrieved in a standard fashion, transported from the donor hospital to our center under standard conditions of cold storage in a low potassium dextran solution (Perfadex; Vitrolife, Gothenburg, Sweden), and placed in the EVLP system. The organs were then perfused for 4 to 6 hours with hourly functional assessments. Lungs with a $\mathrm{PaO}_{2} / \mathrm{FIO}_{2}(\mathrm{P} / \mathrm{F})$ of $400 \mathrm{~mm} \mathrm{Hg}$ or greater and stable or improving pulmonary artery pressure, airway pressures, or dynamic compliance were considered transplantable. Lungs were excluded for transplantation if the $\mathrm{P} / \mathrm{F}$ was less than $400 \mathrm{~mm} \mathrm{Hg}$ or they demonstrated greater than $15 \%$ deterioration in the other functional parameters noted earlier.

Care after LTx, including fluid management, antibiotic prophylaxis, immunosuppression regimens, and surveillance bronchoscopy, was performed for both groups according to current standard practice at the University of Toronto. ${ }^{11}$

\section{Donors}

High-risk donor lungs were defined as those that had any of the following: (1) best P/F less than $300 \mathrm{~mm} \mathrm{Hg}$; (2) pulmonary edema detected on the last chest $\mathrm{X}$-ray or during clinical examination of the lungs; (3) poor lung compliance during examination of the lungs during donor operation; (4) donation after cardiac death (Maastricht categories III and $\mathrm{IV}^{12}$ ); and (5) high-risk history, such as multiple (>10 units) blood transfusions or questionable history of aspiration. Donor lungs with established pneumonias, severe mechanical lung injury defined by gross contusions in more than 1 lobe, and evidence of aspiration of gastric contents were excluded.

\section{Recipients}

All recipients for single or bilateral transplantation and retransplantation were considered EVLP eligible. Recipients on extracorporeal life support (ECLS) before transplantation were excluded from this analysis because they have an increased risk for primary graft dysfunction
(PGD) and have longer stays in the hospital compared with other recipients. ${ }^{13}$

\section{Ex Vivo Lung Perfusion Logistics}

Donor lung offers are made to our clinical lung transplant program through our regional organ procurement organization. Assessments of potential donor lungs are made on the basis of the usual constellation of clinical factors, such as history, $\mathrm{P} / \mathrm{F}$, bronchoscopic examination, radiologic assessment, and direct examination of the organ during the procurement procedure. Donor lungs considered to be high risk are selected for EVLP only after complete assessment of the lungs by our team at the donor hospital. From September 2008 to January 2010, all DCD lungs were subjected to EVLP before LTx as part of the human ex vivo perfusion trial. ${ }^{9}$ Since then, DCD lungs are subjected to EVLP at the discretion of the operating surgeon on call. In general, if DCD lungs meet standard criteria and time from withdrawal of life support therapy to cardiac arrest is less than $60 \mathrm{~min}$ utes, direct transplantation is considered.

Once accepted for EVLP, donor lungs were transported to our center and perfused in the EVLP system located in a sterile operating room environment. Approval for this EVLP study was obtained from our institutional ethics review board and by Health Canada (\#9427-V0689/1-21C, Control \#137622). All recipients receiving lungs after EVLP previously gave consent. They were also informed of the EVLP procedure before LTx.

\section{Ex Vivo Lung Perfusion Technique}

The circuit was primed with 2 liters of Steen Solution (XVIVO, Vitrolife). This solution is a buffered dextran containing an extracellular-type solution with an optimized colloid osmotic pressure developed specifically for EVLP. In addition, $500 \mathrm{mg}$ of methylprednisolone (Solu-Medrol; Sandoz Canada, Boucherville, Canada), $500 \mathrm{mg}$ of imipenem/cilastatin (Primaxin; Merck, Whitehouse Station, NJ), and 3000 IU of heparin (Organon, Canada) were added to the perfusate. After the first hour of EVLP, $500 \mathrm{~mL}$ of circulated perfusate was removed and replenished with $500 \mathrm{~mL}$ of fresh solution. Subsequently, $250 \mathrm{~mL}$ was exchanged every hour until the end of the procedure. No blood products were added to the circuit.

The detailed acellular EVLP technique has been described. ${ }^{14-16}$ In brief, after the lungs were transferred to the XVIVO chamber, the pulmonary artery and left atrium specifically designed cannulas (XVIVO) were connected to the circuit and anterograde flow was started at $150 \mathrm{~mL} / \mathrm{min}$ with the perfusate at room temperature. The temperature of the perfusate was then gradually increased to $37^{\circ} \mathrm{C}$. When $32^{\circ} \mathrm{C}$ was reached (usually $>30$ minutes), ventilation was started and the perfusate flow rate was gradually increased. The flow of gas used to deoxygenate and provide carbon dioxide to the inflow perfusate via a gas exchange membrane was then initiated at $1 \mathrm{~L} / \mathrm{min}$. We used $40 \%$ of the estimated donor cardiac output as the target maximum maintenance perfusate flow rate to perfuse both lungs. Mean pulmonary artery pressures were maintained between 7 and $15 \mathrm{~mm} \mathrm{Hg}$. A positive left atrium pressure was maintained between 3 and $5 \mathrm{~mm} \mathrm{Hg}$ by adjusting the height of the hard-shell reservoir. A protective mode of mechanical ventilation was applied using a tidal volume of $7 \mathrm{~mL} / \mathrm{kg}$ (based on donor ideal body weight) at 7 breaths $/ \mathrm{min}$, positive endexpiratory pressure of $5 \mathrm{cmH}_{2} \mathrm{O}$, and $\mathrm{FiO}_{2}$ of $21 \%$. The lungs were recruited with inspiratory holds to a peak airway pressure of $20 \mathrm{cmH}_{2} \mathrm{O}$ every hour. For the evaluation of lung function, $\mathrm{FIO}_{2}$ was increased to $100 \%$, tidal volumes were increased to $10 \mathrm{~mL} / \mathrm{kg}$, and respiratory rate was increased to 10 breaths/min for 5 minutes. The $\mathrm{pH}, \mathrm{pCO}_{2}$, electrolytes, and glucose were maintained at physiologic levels in the perfusate.

At the end of EVLP, the lung block was cooled down in the circuit to $10^{\circ} \mathrm{C}$ in a 10-minute period. Thereafter, perfusion and ventilation were stopped $\left(\mathrm{FIO}_{2}\right.$ was increased to $50 \%$ for lung storage), and the trachea was clamped to maintain the lungs in an inflated state. The lungs were then statically preserved at $4^{\circ} \mathrm{C}$ in Perfadex until transplantation.

Lung function was evaluated every hour as follows: P/F in pulmonary vein effluent $(\mathrm{mm} \mathrm{Hg})$, pulmonary artery pressure $(\mathrm{mm} \mathrm{Hg})$, lung dynamic 
compliance $\left(\mathrm{mL} / \mathrm{cmH}_{2} \mathrm{O}\right)$, and peak airway pressures $\left(\mathrm{cmH}_{2} \mathrm{O}\right)$. Plain ex vivo lung $\mathrm{X}$-rays and flexible bronchoscopy were performed at 1 hour and 3 hours of EVLP.

\section{Study End Points}

The primary end point was International Society for Heart and Lung Transplantation PGD grade $3^{17}(\mathrm{P} / \mathrm{F}<200 \mathrm{~mm} \mathrm{Hg})$ at 72 hours postLTx. Secondary end points were need for ECLS, time of mechanical ventilation, ICU and hospital lengths of stay, incidence of bronchial complications requiring intervention, 30-day mortality, and proportional survival.

\section{Statistical Analysis}

All statistics were calculated with GraphPad Prism 5 (GraphPad Software Inc, La Jolla, Calif). Results are given as median and ranges. A nonparametric Mann-Whitney test was performed to compare numeric data, and a Fisher exact test was used for categoric data. For differences in lung P/Fs over 4 hours of EVLP within the same group at several time points, repeated-measures analysis of variance was used. Two-way analysis of variance was used for comparison of ex vivo P/Fs between the 2 groups. Kaplan-Meier curves were used for survival plots, and the log-rank test was used to compare proportional survival from EVLP and controls.

\section{RESULTS}

From September 2008 to December 2011 (39 months), 317 LTxs were performed at the University of Toronto. Fourteen transplants were performed in patients bridged with ECLS and therefore excluded from this analysis. A total of 253 consecutive transplants were performed after conventional assessment and preservation (controls), and 50 transplants were performed after EVLP assessment/treatment (22 [44\%] were Maastricht category III DCDs ${ }^{12}$ and 28 [56\%] were brain death donors [BDDs]) (Figure 1). Eight additional donor lungs were subjected to EVLP but were not transplanted because they did not meet functional criteria for transplantation. Of these 8 rejected lungs, 4 were from BDDs and 4 were from DCDs, with a range of donor $\mathrm{P} /$ F from 92 to $420 \mathrm{~mm} \mathrm{Hg}$, and aspiration was detected during more detailed examination of the airways during EVLP bronchoscopy in 2 cases. All BDDs were considered high risk according to donor selection criteria. Approximately

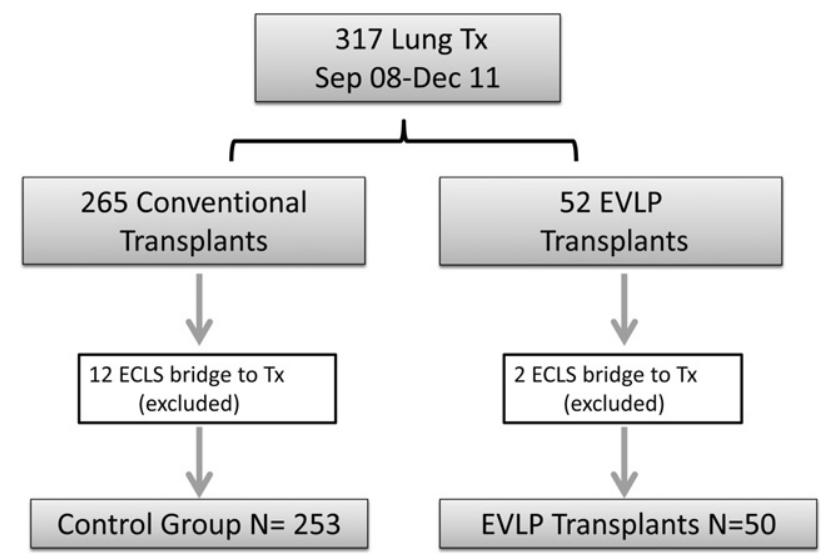

FIGURE 1. Study diagram. ECLS, Extracorporeal life support; EVLP, ex vivo lung perfusion; $T x$, transplantation.

half of the DCDs (12/22) had acceptable P/Fs, but they were included in the EVLP arm as part of inclusion criteria during our initial trial. ${ }^{9}$

Baseline donor lung characteristics were significantly different in the EVLP group compared with controls (Table 1). Donor lungs in the EVLP group had significantly worse gas exchange function (median best donor P/F, 334 $\mathrm{mm} \mathrm{Hg}$ [range, 143-532 $\mathrm{mm} \mathrm{Hg}$ ] vs $452 \mathrm{~mm} \mathrm{Hg}$ [range, $256-590 \mathrm{~mm} \mathrm{Hg}$ ] in controls; $P=.0001$ ) and more abnormalities on chest $\mathrm{x}$-rays $(67 \%$ vs $45 \%, P=.001)$.

Ex vivo gas exchange function, peak airway pressure, and dynamic compliance were significantly better in lungs used after EVLP compared with lungs that were rejected after EVLP (Figure 2). The median P/F ratios in the donor and after 1 hour and 4 hours of ex vivo perfusion were $334 \mathrm{~mm}$ $\mathrm{Hg}, 478 \mathrm{~mm} \mathrm{Hg}$, and $513 \mathrm{~mm} \mathrm{Hg}$, respectively $(P=.0001$; donor $\mathrm{P} / \mathrm{F}$ vs 1 hour and 4 hours). X-ray of the lung block was performed at 1 hour and 3 hours of EVLP. Lungs selected for transplantation demonstrated stable or improved $\mathrm{x}$-ray findings, such as reduced pulmonary edema.

Table 1 summarizes the recipient and transplantation characteristics. There were no significant differences between the 2 groups with regard to relevant baseline characteristics, such as age or medical diagnosis. Medical diagnoses of patients receiving EVLP lungs were emphysema $(\mathrm{n}=19)$, pulmonary fibrosis $(\mathrm{n}=14)$, cystic fibrosis $(\mathrm{n}=12)$, and other $(\mathrm{n}=5)$.

EVLP recipients tended to have less PGD 3 at 72 hours after LTx (EVLP $2 \%$ vs control $8.5 \% ; P=.14$ ) (Table $2)$. One patient $(2 \%)$ in the EVLP group and 7 patients $(2.7 \%)$ in the control group required ECLS for PGD $(P=1.00)$. The median time to extubation and ICU and hospital lengths of stay were 2,4 , and 20 days, respectively, in the EVLP group and 2, 4, and 23 days, respectively, in the control group $(P>.05)$. The incidence of bronchial complications requiring intervention was the same in both groups

TABLE 1. Donor, recipient, and transplantation characteristics

\begin{tabular}{lccc}
\hline \multicolumn{1}{c}{ Donor variable } & $\begin{array}{c}\text { EVLP } \\
(\mathbf{n}=\mathbf{5 0})\end{array}$ & $\begin{array}{c}\text { Controls } \\
(\mathbf{n}=\mathbf{2 5 3})\end{array}$ & $\begin{array}{c}\boldsymbol{P} \\
\text { value }\end{array}$ \\
\hline Age (y) & 45 & 45 & .52 \\
DCD (\%) & 44 & 5.1 & .0001 \\
Best P/F ratio (mm Hg) & 334 & 452 & .0001 \\
Chest X-ray abnormalities (\%) & 67 & 45 & .001 \\
Positive BAL cultures (\%) & 70 & 55 & .05 \\
Recipient variable & & & \\
Age & 56 & 56 & .68 \\
Diagnosis of pulmonary fibrosis or & 32 & 38.7 & .42 \\
$\quad$ PAH (\%) & & & \\
Transplantation variable & & & \\
Bilateral (\%) & 76 & 88 & .04 \\
Retransplantation (\%) & 2 & 3.5 & 1.00 \\
Cardiopulmonary bypass (\%) & 30 & 39 & .26 \\
\hline$E V L P$, Ex vivo lung perfusion; $D C D$, donation after cardiac death; $P / F, \mathrm{PaO}_{2} / \mathrm{FIO}_{2}$; \\
$B A L$, bronchoalveolar lavage; $P A H$, pulmonary arterial hypertension.
\end{tabular}



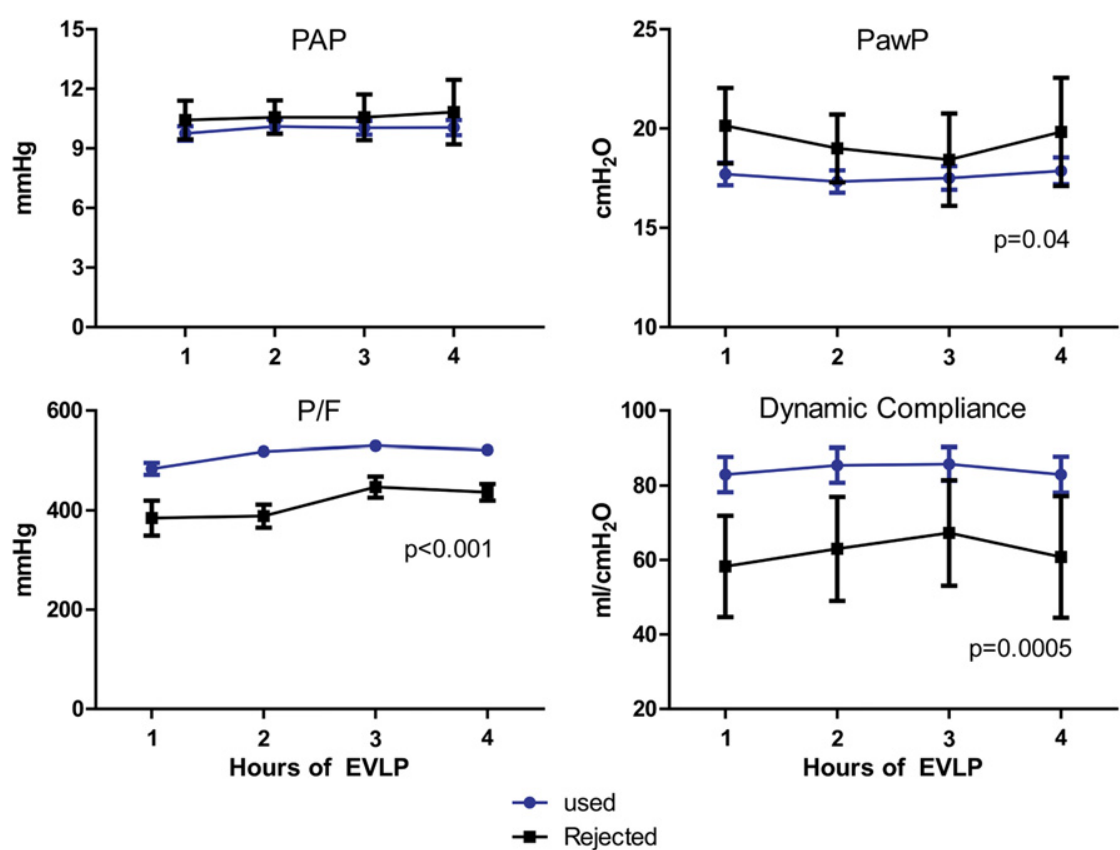

FIGURE 2. Lung function during EVLP in lungs used $(n=50)$ and rejected $(n=8)$ for transplantation. Gas exchange, peak airway pressure, and dynamic compliance were significantly better in lungs used after EVLP compared with lungs that were rejected. No differences were observed in pulmonary artery pressures. PAP, Pulmonary artery pressure; PawP, peak airway pressure; $P / F, \mathrm{PaO}_{2} / \mathrm{FIO}_{2} ; E V L P$, ex vivo lung perfusion.

$(4 \%, P=1.00)$. Two of 50 patients $(4 \%)$ died within 30 days in the EVLP group compared with 9 of 253 patients $(3.5 \%)$ in the control group $(P=1.00)$. One-year survival was $87 \%$ in the EVLP group and $86 \%$ in the control group $(P=1.00)$, and 3 -year survival was $70 \%$ in the EVLP group and $72 \%$ in the control group $(P=.86)$ (Figure 3, $A$ ). Causes of death in the EVLP group are shown in Table 3. Because DCD lungs subjected to EVLP had better last donor $\mathrm{P} / \mathrm{F}$ ratio compared with the subgroup BDD lungs subjected to EVLP (363 vs $285 \mathrm{~mm} \mathrm{Hg}, P=.02$ ), a subgroup

TABLE 2. Recipient outcomes in ex vivo lung perfusion and conventional transplants

\begin{tabular}{|c|c|c|c|}
\hline Variable & $\begin{array}{c}\text { EVLP } \\
(\mathbf{n}=\mathbf{5 0})\end{array}$ & $\begin{array}{l}\text { Controls } \\
(\mathbf{n}=\mathbf{2 5 3})\end{array}$ & $\begin{array}{c}P \\
\text { value }\end{array}$ \\
\hline PGD 3 at $72 \mathrm{~h}(\%)$ & 2 & 8.5 & .14 \\
\hline ECLS (\%) & 2 & 2.7 & 1.00 \\
\hline Mechanical ventilation (d) & & & .30 \\
\hline Median & 2 & 2.2 & \\
\hline Range & 1-101 & $1-43$ & \\
\hline ICU stay (d) & & & .32 \\
\hline Median & 4 & 4.5 & \\
\hline Range & $1-100$ & $1-257$ & \\
\hline Hospital stay (d) & & & .11 \\
\hline Median & 20 & 23 & \\
\hline Range & $7-156$ & $1-299$ & \\
\hline 30-d mortality ( $\%$ ) & 4 & 3.5 & 1.00 \\
\hline $\begin{array}{l}\text { Anastomotic stricture } \\
\text { requiring intervention }(\%)\end{array}$ & 4 & 4 & 1.00 \\
\hline
\end{tabular}

analysis was performed. No differences were observed in the survival of recipients receiving lungs from either donor type after EVLP (Figure 3, B). Likewise, no survival differences were observed in recipients receiving EVLP lungs for which the donor $\mathrm{P} / \mathrm{F}$ ratio was less than $300 \mathrm{~mm} \mathrm{Hg}$ (Figure 3, C).

\section{DISCUSSION}

Although the demand for LTx far outweighs the number of donor lungs available, the use rate of potential donor organs in LTx is the lowest among solid-organ transplantation, between $15 \%$ and $20 \%$. The main reason for the conservative donor lung selection is PGD, a clinical entity that resembles acute lung injury and occurs within 72 hours of transplantation. ${ }^{18}$ PGD can occur when an injured lung is implanted into a recipient, and the condition remains a challenging clinical problem for which there is still no reliably effective pharmacotherapy. Furthermore, there is a lack of accurate donor lung assessment tools to predict whether a given donor lung will function properly immediately after transplantation. ${ }^{19}$ Lungs that appear "questionable" are often declined by transplant clinician, leading to wastage of potentially usable donor lungs. ${ }^{20}$

This study reviewed our experience with normothermic EVLP as a means to reevaluate the function and improve the quality of injured donor lungs. Fifty transplants of 58 perfusions ultimately met ex vivo functional criteria and were transplanted. This is the largest experience to date using clinical EVLP. After our initial clinical series, several 


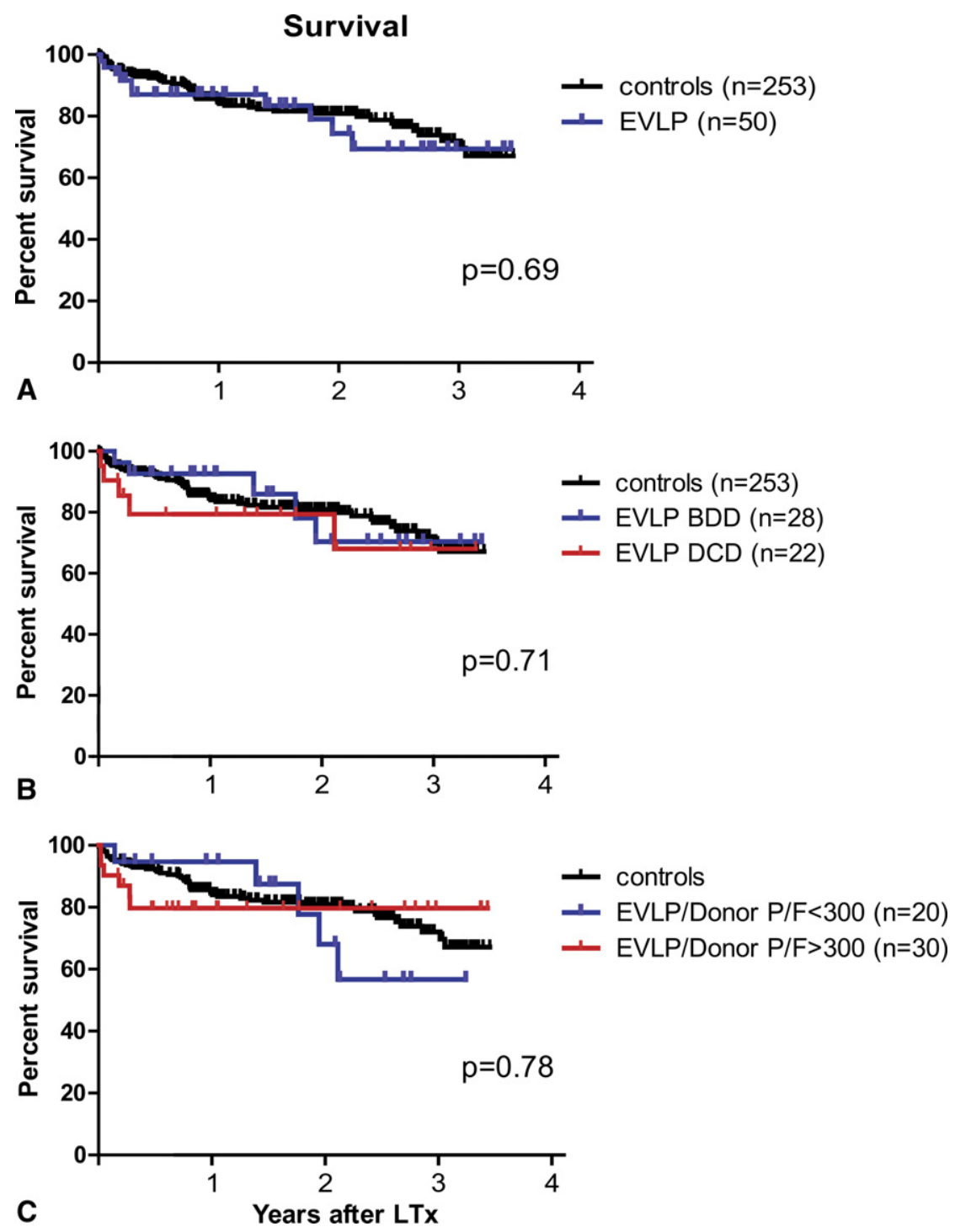

FIGURE 3. Proportional survival of EVLP and conventional transplants. A, No differences were observed in the 2 groups $(P=.69)$. B, No differences were observed in the survival of recipients receiving lungs from either donor types (BDDs or DCDs) after EVLP $(P=.71)$. C, Recipients who received EVLP lungs in which the donor $\mathrm{P} / \mathrm{F}$ ratio was less than $300 \mathrm{~mm} \mathrm{Hg}$ had similar outcomes compared with recipients who received donor lungs with a $\mathrm{P} / \mathrm{F}$ ratio more than $300 \mathrm{~mm} \mathrm{Hg}(P=.78) . B D D$, Brain death donor; $D C D$, cardiac death donor; $E V L P$, ex vivo lung perfusion; $L T x$, lung transplantation.

other centers have started the use of EVLP using the technique described by our group, ${ }^{14}$ and outcomes have been encouraging demonstrating the reproducibility of the procedure.

Donor lungs included in the study had impaired gas exchange or other concerning findings, such as evidence of bilateral infiltrates on chest x-ray, clinical evidence of pulmonary edema, and suspected aspiration, or concerning history factors, such as multiple blood transfusions in the context of trauma. All BDDs $(\mathrm{n}=28)$ were considered high-risk donors and would not be transplanted without the availability of EVLP. The remaining 22 donors were from DCDs. We currently subject most DCD lungs to EVLP assessment before LTx. Although small clinical series, including our own, have shown good outcomes after DCD LTx ${ }^{21-27}$ without the use of EVLP, we still believe this is a less predictable organ in regard to the development of PGD. We would consider the use of DCD lungs even with a 2-hour interval between withdrawal of life support to arrest if they are reassessed with EVLP. This demonstrates the impact that EVLP might have on lung use rates even in a lung transplant center with an already high use rate $(30 \%-40 \%)$ of donor lungs from multiorgan donors. We understand that the definition of "high-risk" donors varies from center to center and may be broader in more "conservative" lung transplant centers than in more "aggressive" centers, but in either case, EVLP will give clinicians in either setting the confidence to transplant 
TABLE 3. Causes of death in ex vivo lung perfusion recipients

\begin{tabular}{lcl}
\hline Medical diagnosis & Survival (d) & \multicolumn{1}{c}{ Cause of death } \\
\hline COPD/emphysema & 644 & CGD \\
COPD/emphysema & 771 & Bacterial pneumonia \\
Cystic fibrosis & 66 & Cepacia sepsis \\
Pulmonary fibrosis & 710 & CGD \\
Retransplant & 100 & Fungus infection \\
Pulmonary fibrosis & 17 & Retroperitoneal hemorrhage \\
Pulmonary fibrosis & 7 & Gram sepsis \\
PPH & 507 & Bacterial pneumonia \\
Cystic fibrosis & 52 & Cepacia sepsis \\
Pulmonary fibrosis & 101 & Bacterial pneumonia \\
& & (bronchial stenosis) \\
\hline COPD, Chronic obstructive pulmonary disease; $C G D$, chronic graft dysfunction; \\
PPH, primary pulmonary hypertension.
\end{tabular}

more lungs, using donors that are beyond their own "comfort zone" of use. EVLP likely added a $10 \%$ to $15 \%$ increase in the number of transplants at our center in the past 3 years, considering that this was the additional proportion of lungs that would be discarded by our group if EVLP was not available. Although the number of transplants varied from 85 to 102 per year in these 3 years, the number of multiorgan BDDs had actually decreased in our organ procurement organization, and yet we were able to keep our lung transplant numbers at a consistent level. Also of note, in 2011 , our 30 -day mortality was only $2 \%$, despite performing transplantations in sicker recipients. We believe EVLP has a role in that process because some extended lungs for which we would push the limits in the past are now first checked with EVLP for assurance of performance.

Although no specific EVLP P/F (cutoff) can be established from this study to decide when a lung can be safely transplanted after EVLP, P/F greater than $400 \mathrm{~mm} \mathrm{Hg}$ and stable pulmonary artery pressure, peak airway pressure, and lung compliance during 4 hours of perfusion translates into successful post-transplant outcomes. The significant increase in the P/F ratio in the first hour of EVLP observed by our group and by others is most likely a reflection of lung recruitment and optimization of ventilation/perfusion matching in the lung, and thus on its own should be interpreted with caution. To that end, we find that a perfusion time of at least 3 hours is required before making a decision on lung use. In the future, the use of lung specific biomarkers will further assist in the precision of assessment during EVLP. The increase of lactate in the perfusate did not correlate with post-transplant outcomes. ${ }^{28}$

Despite EVLP lungs being more injured than conventional transplants, they had low levels of PGD 3, only $2 \%$ at 72 hours, compared with $8.5 \%$ in controls. Likewise, time on mechanical ventilation, ICU stay, and length of hospitalization were acceptable and comparable to those of conventional transplants. One-year survival was $87 \%$ percent in the EVLP group compared with $86 \%$ in controls. We also stratified the EVLP survival analysis in recipients receiving lungs from $\mathrm{BDD}$ versus DCD and in recipients receiving lungs in which the best donor $\mathrm{P} / \mathrm{F}$ was less than 300 $\mathrm{mm} \mathrm{Hg}$ versus more than $300 \mathrm{~mm} \mathrm{Hg}$. Again, no differences were observed in these 2 subgroups.

Although no direct cause of death could be attributed to EVLP (Table 3), 1 patient had anastomotic stricture leading ultimately to bacterial pneumonia and death. Although we cannot rule out EVLP as a contributing factor for this specific airway complication, the general incidence of anastomotic complications was low in this cohort of patients $(4 \%)$.

\section{CONCLUSIONS}

The present study demonstrates that 4-hour normothermic acellular EVLP is safe and provides similar outcomes compared with conventionally selected and transplanted donor lungs. It is a useful technique to improve and reassess the function of high-risk donor lungs, increasing the safe use of lungs. In the future, perhaps every organ will go through an EVLP "check" and reconditioning before transplantation; however, the benefit of this concept needs to be demonstrated in a randomized clinical trial. The present study also provides the basis for further clinical studies using EVLP as a platform for more advanced targeted pharmacologic and molecular therapeutic strategies to treat specific donor lung injuries ex vivo. ${ }^{16}$ Ultimately, this opens the door for an approach of "personalized medicine for the organ"- the opportunity to diagnose and specifically treat or repair the donor organ to optimize outcome after transplantation.

\section{References}

1. Klein AS, Messersmith EE, Ratner LE, Kochik R, Baliga PK, Ojo AO. Organ donation and utilization in the United States, 1999-2008. Am J Transplant. 2010;10: 973-86.

2. de Perrot M, Liu M, Waddell T, Keshavjee S. Ischemia-reperfusion-induced lung injury. Am J Respir Cell Mol Biol. 2003;28:616-25.

3. Angel LF, Levine DJ, Restrepo MI, et al. Impact of a lung transplantation donormanagement protocol on lung donation and recipient outcomes. Am J Respir Crit Care Med. 2006;174:710-6.

4. Avlonitis VS, Wigfield CH, Kirby JA, Dark JH. The hemodynamic mechanisms of lung injury and systemic inflammatory response following brain death in the transplant donor. Am J Transplant. 2005;5:684-93.

5. Keshavjee SH, Yamazaki F, Cardoso PF, McRitchie DI, Patterson GA Cooper JD. A method for safe twelve-hour pulmonary preservation. $J$ Thorac Cardiovasc Surg. 1989;98:529-34.

6. Fischer S, Matte-Martyn A, De Perrot M, et al. Low-potassium dextran preservation solution improves lung function after human lung transplantation. $J$ Thorac Cardiovasc Surg. 2001;121:594-6.

7. Southard JH, Belzer FO. Organ preservation. Annu Rev Med. 1995;46:235.

8. Steen S, Sjoberg T, Pierre L, Liao Q, Eriksson L, Algotsson L. Transplantation of lungs from a non-heart-beating donor. Lancet. 2001;357:825-9.

9. Cypel M, Yeung JC, Liu M, et al. Normothermic ex vivo lung perfusion in clinical lung transplantation. N Engl J Med. 2011;364:1431-40.

10. de Perrot M, Bonser RS, Dark J, et al. Report of the ISHLT Working Group on Primary Lung Graft Dysfunction part III: donor-related risk factors and markers. J Heart Lung Transplant. 2005;24:1460-7.

11. de Perrot M, Chaparro C, McRae K, et al. Twenty-year experience of lung transplantation at a single center: Influence of recipient diagnosis on long-term survival. J Thorac Cardiovasc Surg. 2004;127:1493-501. 
12. Kootstra G, Daemen JH, Oomen AP. Categories of non-heart-beating donors. Transplant Proc. 1995;27:2893-4.

13. Hammainen P, Schersten H, Lemstrom K, et al. Usefulness of extracorporeal membrane oxygenation as a bridge to lung transplantation: a descriptive study. J Heart Lung Transplant. 2011;30:103-7.

14. Cypel M, Yeung JC, Hirayama S, et al. Technique for prolonged normothermic ex vivo lung perfusion. J Heart Lung Transplant. 2008;27:1319-25.

15. Cypel M, Rubacha M, Yeung J, et al. Normothermic ex vivo perfusion prevents lung injury compared to extended cold preservation for transplantation. Am J Transplant. 2009;9:2262-9.

16. Cypel M, Liu M, Rubacha M, et al. Functional repair of human donor lungs by IL-10 gene therapy. Sci Transl Med. 2009;1:4ra9.

17. Christie JD, Carby M, Bag R, Corris P, Hertz M, Weill D. Report of the ISHLT Working Group on Primary Lung Graft Dysfunction part II: definition. A consensus statement of the International Society for Heart and Lung Transplantation. J Heart Lung Transplant. 2005;24:1454-9.

18. Lee JC, Christie JD, Keshavjee S. Primary graft dysfunction: definition, risk factors, short- and long-term outcomes. Semin Respir Crit Care Med. 2010;31: 161-71.

19. Kaneda H, Waddell TK, de Perrot M, et al. Pre-implantation multiple cytokine mRNA expression analysis of donor lung grafts predicts survival after lung transplantation in humans. Am J Transplant. 2006;6:544-51.

20. Ware LB, Wang Y, Fang X, et al. Assessment of lungs rejected for transplantation and implications for donor selection. Lancet. 2002;360:619-20.

21. Cypel M, Yeung JC, Keshavjee S. Novel approaches to expanding the lung donor pool: donation after cardiac death and ex vivo conditioning. Clin Chest Med. 2011;32:233-44.

22. De Oliveira NC, Osaki S, Maloney JD, et al. Lung transplantation with donation after cardiac death donors: long-term follow-up in a single center. J Thorac Cardiovasc Surg. 2010;139:1306-15.

23. Puri V, Scavuzzo M, Guthrie T, et al. Lung transplantation and donation after cardiac death: a single center experience. Ann Thorac Surg. 2009;88:1609-15.

24. Snell GI, Levvey BJ, Oto T, et al. Early lung transplantation success utilizing controlled donation after cardiac death donors. Am J Transplant. 2008;8: 1282-9.

25. Cypel M, Sato M, Yildirim E, et al. Initial experience with lung donation after cardiocirculatory death in Canada. J Heart Lung Transplant. 2009;28: $753-8$.

26. Erasmus ME, Verschuuren EA, Nijkamp DM, Vermeyden JW, van der Bij W. Lung transplantation from nonheparinized category III non-heart-beating donors. A single-centre report. Transplantation. 2010;89:452-7.

27. Mason DP, Murthy SC, Gonzalez-Stawinski GV, et al. Early experience with lung transplantation using donors after cardiac death. J Heart Lung Transplant. 2008; 27:561-3.

28. Koike T, Yeung JC, Cypel M, et al. Kinetics of lactate metabolism during acellular normothermic ex vivo lung perfusion. J Heart Lung Transplant. 2011;30: 1312-9.

\section{Discussion}

Dr R. Duane Davis (Durham, NC). First a disclosure. We are being supported by Vitrolife. They funded the US trial.

Marcelo, congratulations on an excellent presentation. You and your colleagues at the University of Toronto have again demonstrated the safety and efficacy of using EVLP to enable the transplantation of lungs that would previously not have been used by your group. In the United States, lung disease is the fourth most common cause of death; it accounts for approximately 125,000 deaths per year. We perform approximately 2000 lung transplants per year. So you could say there is an approximate 122,000 shortfall in the number of transplants that potentially could be done. Obviously that is a bit of an overestimation; not of all those would be appropriate candidates. But using this technology, we may start to be able to apply LTx more effectively for societal needs. As you have mentioned, only approximately $17 \%$ of the lungs in the United States from consented donors actually yield lungs for transplant. So my questions are going to be primarily focused on the overall impact that EVLP may have on LTx.

In your group's experience, $86 \%$ of the lungs treated with EVLP were subsequently transplanted, and they now account for approximately $20 \%$ of the overall transplants you perform at Toronto. However, this yield seems to be substantially different than what we are seeing in the US trial. Currently, approximately $54 \%$ of lungs ( $\sim 1$ of 2 ) treated with EVLP are being transplanted. This is fairly consistent with data from the United Kingdom and other countries.

What do you think are the differences? Are you using lungs that we would have conventionally used or lungs that may actually fit better with the operating room schedule, that is, operations are occurring at $2 \mathrm{Am}$, and this allows you to do it during the daytime?

Dr Cypel. That is an interesting point. To be relatively direct about that, none of these perfusions were performed because we would be able to perform transplantations at a less disruptive time. It is an interesting concept and totally feasible, because we have shown that we can safely keep these organs 12 hours in the system without any added injury. But that was not the case in this specific population.

The main difference in our higher use rates compared with the other groups that more recently started with EVLP is based on the experience that our group has with the procedure. We have extensive laboratory research, performing EVLP in more than 100 large animals and in rejected human lungs before starting a clinical trial, and this is different than the current scenario at other centers. That is part of the answer. I also think it is related to the donor selection. More recently, we have pushed the limits further; consequently, we have used fewer lungs after EVLP. I think it depends on the donor selection criteria.

Dr Davis. Although the overall cohort of patients receiving EVLP lungs had essentially identical outcomes to those of patients receiving conventional lungs, the patients receiving EVLP lungs from the DCDs had an approximate 20\% 6-month mortality. Although this is not statistically significant, it does raise some concern, particularly when we are starting to think about going into the uncontrolled DCD or the Maastricht categories 1 and 2, where we could substantially increase the donor pool.

Does this raise concerns, and have you looked at things such as warm ischemic time in these DCDs to try to get an early signal? Although there are few events, it would be nice to know if there are things that we should avoid in the DCD population.

Dr Cypel. We have looked at the causes of death in these 4 recipients who received DCD lungs after EVLP and died in the first 6 months. Two of those were patients who had a diagnosis of cepacia-positive cystic fibrosis and ultimately died of cepacia sepsis after being discharged from the hospital. The third patient had a massive retroperitoneal hematoma after being anticoagulated for atrial fibrillation, and the fourth patient died of gram-negative sepsis, so the deaths were not really related to the quality of the graft. We are happy with our low incidence of PGD after transplantation using DCD lungs.

In regard to your question of the interval of time from withdrawal of life-support therapies to cardiac arrest, there was really no difference, but as you mentioned, I think the numbers are small. The Australian experience has shown that perhaps there is a signal there, but I think when we put all the data together from the 
International Society of Heart and Lung Transplantation, we will be able to discriminate that better.

Dr Davis. My final question is basically to look in the crystal ball. We are currently performing 2000 lung transplants. You say that approximately $20 \%$ of the lungs you use are being treated now with EVLP, but you actually have been static at approximately 100 lung transplants per year. So even though you have this new technology, it has not seemed to increase the volume of transplants you are performing. The goal in the United States is to achieve $40 \%$ to $50 \%$ use or to double or triple the number of transplants.

With EVLP as it is now, where do you think it is going to actually drive the number of transplants in the United States without doing things such as gene therapy or other resuscitation therapies on the lungs?
Dr Cypel. For the first part of the question, our numbers have been stable at 100 in the last 2 years; the organ donation rates in our organ procurement organization have decreased in the last 2 years, and all solid-organ transplant numbers have decreased in our institution, and we are able to keep our number stable. I think it did make a contribution on that end.

The major contribution of EVLP will not be for the large number of transplant centers with high use rates (eg, Duke or Toronto) and that already use $40 \%$ of the organs. Their margin of increase is not that large, but if we look at the majority of lung transplant centers that use less than $10 \%$ of the offered lungs, that is where we can make a major impact, increasing the number of organs available.

Dr Davis. Again, congratulations. 